\title{
The Role of Transcendental Leadership to Increase Organization Performance through Workers Job Satisfaction
}

\author{
Florentina K. Tehubijuluw
}

\begin{abstract}
The role of the transcendental leader is needed to assist in achieving the workers happiness and satisfaction with their jobs and in the same time helping the organization to achieve business objectives and allow the employees to flourish within the organization. The main objective of this study is to analyze the role of transcendental leadership to achieve organization performance using workers job satisfaction as mediating variable in Indonesia's property industries. All the data is statistically analyzed using the Structural Equation Method model. Findings of this research indicate that there's a positive effect between transcendental leadership; workers job satisfaction and organization performance; in which workers job satisfaction has the greatest effect into organization performance, meanwhile the transcendental leadership doesn't have significant effect directly into organization performance. The future research should consider the importance role of the leader for organization performance by setting-up core value within organization. This study is the first, to the researcher's knowledge, to see the effect of all dimensions of transcendental leadership into workers job satisfaction and finally to improve organization performance.
\end{abstract}

Index Terms-Transcendental leadership, workers job satisfaction, organization performance.

\section{INTRODUCTION}

The nature of work appears to have changed substantially. Work has been transformed into the place in which individuals develop themselves and people are searching for meaning in work. According to Palmer [1], spirituality at the workplace has been growing. The founders of the organization initiate the core values which give guidance for the whole organization. As the leaders, they will play vital roles in determining the fate of their organizations and create many organizational outcomes using their decision-making power. The leaders will help the workers not to lose their hope in the hard times of their work and provide services to the customers with the good spirit. The leader must able to encourage or create a culture that provides meaning caring, wholeness, purpose, and being part of something greater to all employees within organization.

Organizations need to understand that if their employees are happy, they will be more productive and creative which in

Manuscript received June 2, 2014; revised August 3, 2014.

Florentina K Tehubijuluw is with STMIK Jibes \& STIE Wiyatamandala, Serpong, Banten, Indonesia (e-mail: florentehu@yahoo.com). turn will work as a win-win situation for both the employees and the organization. With the growing competition in the market place, it is important that the employees perform to their full extent so as not to satisfy the customers but to delight them. One of the goals of every leader is to improve the performance of their organization. Sales should increase, the number of turnovers should decline, the competitive edge should be attained and the reputation should be the best. The many positive traits and characteristics of a spiritual workplace would also generate a fresh and invigorating organizational culture which positively influences the organizational structure toward many positive outcomes in productivity, performance, effectiveness, and efficiency [2]-[4].

The escalation of income and the purchasing power of the people in general, as well as household consumption for the necessities in particular, make the property industry in Indonesia flourish with the growing rate at average 12.5\% yearly [5]. Some key players who had experienced in those industries enjoyed their promising businesses by diversifying their line businesses into various projects. Even the main businesses are more diversified; the owner chose the professional management team to running their business. The owners put the spiritual core value as a guidance to do the business; emphasize the implementation of spiritual intelligence within organization; focus to make all employees happy in order to get higher company performances. He also acts as a transcendental leader by emphasizing spiritual value in the organization and develops the corporate social responsibility (CSR) program to increase and improve the welfare of the society. Since the companies are now getting bigger and more diversified in the line of business, the property company will face some challenges to maintain their strong performances. The companies have to pay attention keeping these spiritual value established by the owners to increase the organization performance that depends on the worker's job satisfaction.

Based on the explanation of the background, the research question is formulated as follows: What is the role of transcendental leadership to increase organizational performance? Meanwhile, the proposed research study was to answer the research question mentioned previously: to understand the importance role of transcendental leadership to increase organizational performance by considering the aspects of workers job satisfaction.

The aim of this current study was for further research to focus more on the leader's role in focusing some spirituality aspects in the organization to gain a strong workers job satisfaction. 


\section{THEORETICAL FRAMEWORK AND HYPOTHESES DEVELOPMENT}

\section{A. Transcendental Leadership}

Organizational leaders have a major role in reinforcing and developing spirituality at work [6]. The leaders whose mission is to train their followers mentally, emotionally, and spiritually have to particularly learn to integrate their IQ, EQ and SQ in the first place [7]. An important part of managing an organization's culture is attracting and choosing those individuals who share the same values as the organization [8]. Spiritual leadership comprises the values, attitudes and behaviors necessary to intrinsically motivate oneself and satisfy fundamental needs for spiritual well-being through calling and membership [9]. Zohar and Marshall [10] stated that management played a crucial role in establishing, shaping and maintaining the organizational culture since they're able to prioritize and establish innovation among employees in the organization and often reflected in employee beliefs, attitudes and behavior which in turn represent needs and motivations.

\section{B. Workers Job Satisfaction}

Sisk and Torrance [11] believe that the spiritual intelligence can deepen an individual's relationship with himself and others, or the larger world in everyday activities. They also can do their tasks with high accuracy, integrity and work ethics and it is expected that they deal with customers more effective. They can establish a better relationship with the customers, the colleagues, the supervisors and other people within organization. Employee's work performance is important to the overall company or organization in order to achieve company's goal, develop products, provide services and attain competitive goal [12].

\section{Organization Performance}

A spiritual business organization can be considered as the new competitive advantage since increased profits and performance has been representative of a spiritual business organization [13]. Employees who demonstrate spiritual traits have a greater understanding to adapt to a changing environment, the ability to trust others, and a high level of commitment to the organization [14]. A spiritual business organization increases employee satisfaction, the values of honesty, trust, respect, responsibility and integrity. A spiritual business organization represents these shared values and as the leadership effectively demonstrates these values with behavior, actions and as these values are up held throughout the organizational culture, employee satisfaction in increased and in the long-run will increase organizational performance including higher profits and success [15].

\section{Conceptual Framework}

The research of Khorsidi and GaneehEbaadi [16] showed the values and culture of the organizations are of significant importance in establishing motivation and inspiration and among employees and reducing employees stress. According to Bass and Avolio [17], organizational leaders have a major role in reinforcing and developing spirituality at work. The leader influences the organization culture by values, connecting with others, practicing spirituality and living a transparent lifestyle and include self-realization and implements a balance between family, work and spirituality [18]. Relating with the previous discussion of the literature review, the conceptual framework proposed in this present study is as follow (Fig. 1):

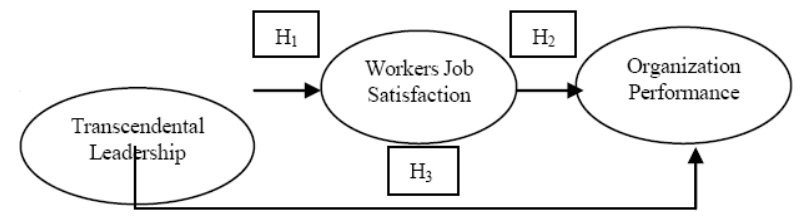

Fig. 1. Research conceptual framework.

\section{E. Research Hypotheses}

1st Hypothesis: There is a positive effect between the transcendental leadership and the workers job satisfaction.

2nd Hypothesis: There is strong effect of workers job satisfaction into the organization performance.

3rd Hypothesis: There is an effect between the transcendental leadership and the organization performance.

\section{Methodology}

\section{A. Measurement and Operational Variable}

Transcendental Leadership. This variable will be measured using dimension of transcendental spirituality leaderships develop by Kendall and Hullin [19], namely as follows: management by common value; give identification to employee; empowerment of employees; spiritual developments of employee; relief spiritual energy of employee; re-informant of self- control; influence in other.

Workers Job Satisfaction. The dimension of worker's job satisfaction will be measured using Job Descriptive Index that was developed by Landy, Shankster \& Kohler [20] and having some indicators: the work nature; the attitude toward supervisors; the relations with co-workers; the opportunities for promotion; salary / benefit and the working condition.

Organization Performance. Chenhall \& Langfield-Smith [21] mentioned that organization performance have six dimensions namely: efficiency; effectiveness; development; satisfaction; innovation and quality.

The research questionnaires in this study consisted two parts. The first part was drawn for collecting demographic information profile of the respondents and the second part of questionnaire represented the main research questions is taken from the previous study which are adjusted with the current respondent. Each question will be measured base on Likert 5th option spectrum coded from: Scale $1=$ Very Disagree, Scale 2 = Disagree, Scale $3=$ Doubtful, Scale $4=$ Agree and Scale $5=$ Very Agree .

Research Design. The research design in this study is hypotheses testing using cross-sectional time dimension; field study research, causality with individual as unit analysis using the Structural Equation Models (SEM) technique and the Lisrel Program. Transcendental leadership is measured by 7 dimensions (X1 to $\mathrm{X} 7$ ), the workers job satisfaction is measured by 6 dimensions ( $\mathrm{Y} 1$ to $\mathrm{Y} 6$ ) and the organization performance is measured by 6 dimensions ( $\mathrm{Y} 7$ to $\mathrm{Y} 12$ ). 
Samples and Data Collection. Statistical sample of this research has been selected from all the employees from the six big developer companies in Tangerang region, Banten Province. Based on SEM rule of thumb [22], it's enough using comparison 5:1 with the minimum of sample $=200$ respondents. Even this research has 19 parameters and only 95 respondents needed as sample, to get a better result, the researcher distribute 200 questionnaires using stratified random sampling.

Validity Testing. By correlating among scores for each item in form of questions using Pearson correlation and the pre-test with critical $t>0.799$ showing that all items have greater correlation value and VALID.

Reliability Testing. Using Cronbach's alpha coefficient and admissible is all values yielded alpha coefficient exceeded the values of 0.50 suggested by Nunnaly [23]. The pre-test showed that the alpha reliability value is greater than 0.789 and VALID.

Test of Model Fit Measurement. In this study, Confirmatory Factor Analysis (CFA) is used.

Structural Model Fit Test. Evaluation on analysis of structural model includes examination of correlation of latent variables in this research. If significance degree reaches alpha $=0.05$ and $t$-value $>=1.96$, then significance of every coefficient that represents causal relation that is hypothesized can be tested systematically.
Test of Structural Model Fitness. From the Goodness-of Fit (GOF) test shows that only AGFI indicator model that shows Marginal Fit with the testing result value is $<0.90$ and this research theory were perfect. The result for goodness for fit testing in this research is as follows:

\begin{tabular}{cccc}
\multicolumn{5}{c}{ TABLE I: DESIGN SUMMARY FOR GoODNESS FOR FIT TESTING MODEL } \\
\hline GOF Indicator & Estimated Value & Testing Result & Conclusion \\
\hline \multicolumn{4}{c}{ Absolute Fit Value } \\
GFI & GFI $\geq 0.90$ & 0.90 & Good Fit \\
RMSEA & RMSEA $<0.08$ & 0.048 & Good Fit \\
\hline \multicolumn{4}{c}{ Incremental Fit Value } \\
NNFI & NNFI $>0.90$ & 0.98 & Good Fit \\
NFI & NFI $>0.90$ & 0.97 & Good Fit \\
AGFI & AGFI $>0.90$ & 0.89 & Marginal Fit \\
RFI & RFI $>0.90$ & 0.96 & Good Fit \\
IFI & IFI $>0.90$ & 0.98 & Good Fit \\
CFI & CFI $>0.90$ & 0.98 & Good Fit \\
\hline \multicolumn{5}{c}{ Source: Data Analysis using LISREL 8.70} \\
\end{tabular}

\section{RESUlTS AND DISCUSSIONS}

Result of Hypothetical Test. Following are the hypotheses testing the effect of transcendental leadership and workers job satisfaction into organizational performance using path diagram (Fig. 2 and Fig. 3).

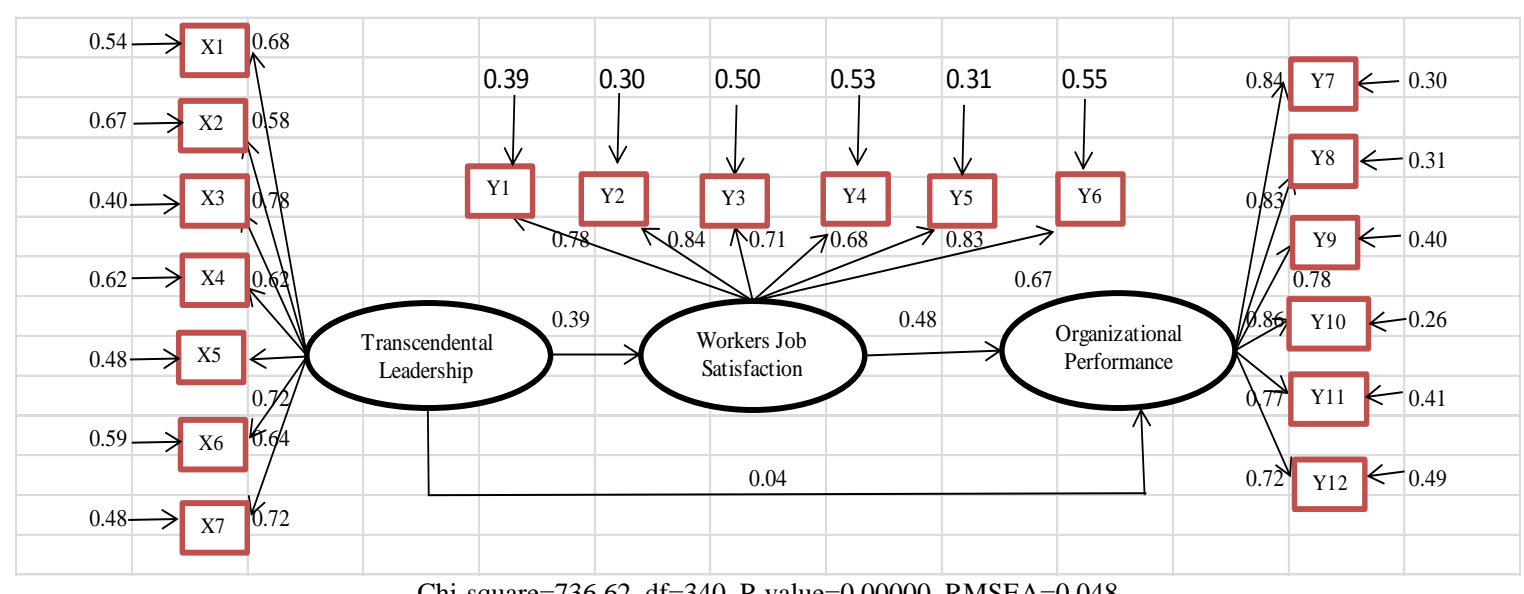

Chi-square $=736.62, \mathrm{df}=340, \mathrm{P}$-value $=0.00000$, RMSEA $=0.048$

Fig. 2. Structural diagram (standardized).

The role of transcendental leadership into organization performance through workers job satisfaction.

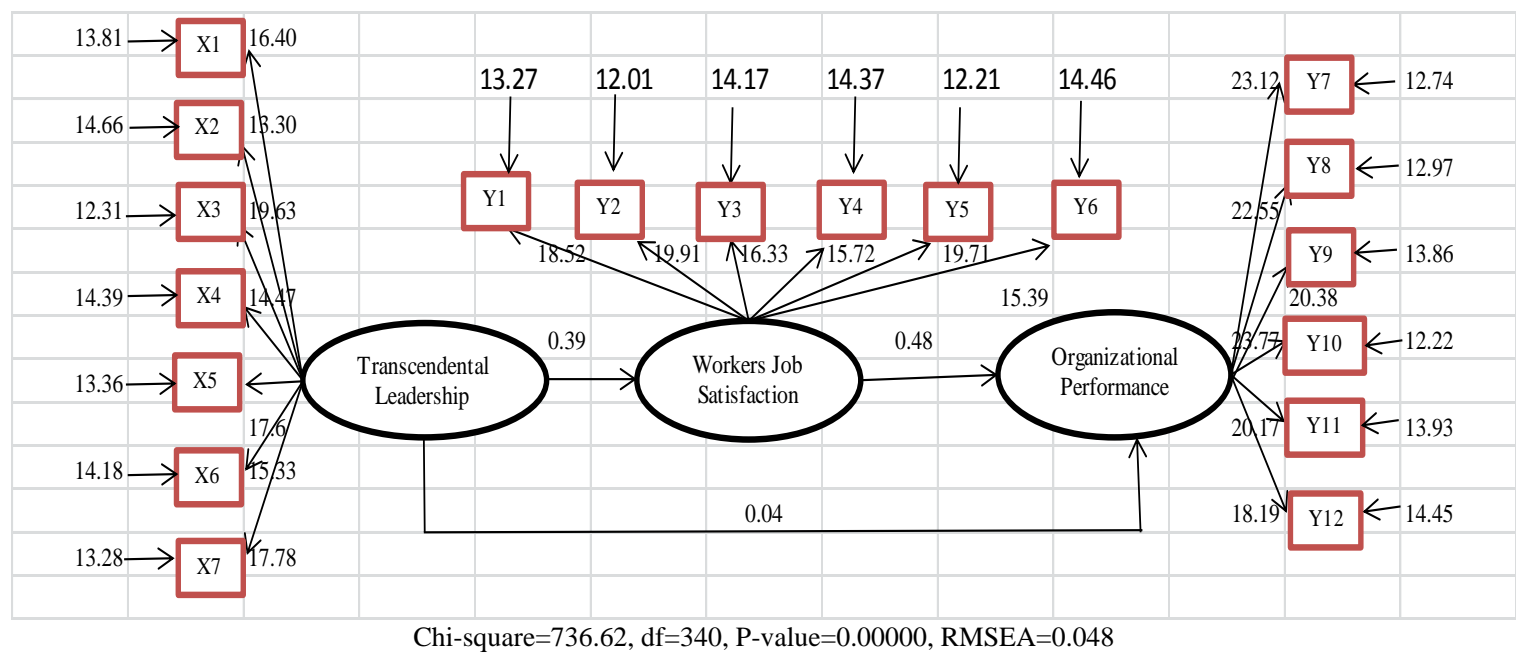

Fig. 3. Structural diagram (t-value)

The role of transcendental leadership into organization performance through workers job satisfaction. 
The results of Hypotheses Testing are shown in Table II:

TABLE II: SUMMARY OF RESULT OF HYPOTHESES TESTING

\begin{tabular}{|c|c|c|c|c|}
\hline Hypotheses & Variables & $\begin{array}{c}\text { Coefficient } \\
\text { Standard }\end{array}$ & t-Value & $\begin{array}{c}\text { Statistical } \\
\text { Conclusion }\end{array}$ \\
\hline $\mathrm{H}_{1}$ & TL $\rightarrow$ WJS & 0.39 & 7.07 & $\begin{array}{c}\text { Data } \\
\text { Supported }\end{array}$ \\
\hline $\mathrm{H}_{2}$ & WJS $\rightarrow$ OP & 0.48 & 8.95 & $\begin{array}{c}\text { Data } \\
\text { Supported }\end{array}$ \\
\hline $\mathrm{H}_{3}$ & TL $\rightarrow$ OP & 0.04 & 0.71 & $\begin{array}{c}\text { Data } \\
\text { Supported }\end{array}$ \\
\hline
\end{tabular}

In which: TL $=$ Transcendental Leadership; WJS = Workers Job Satisfaction and $\mathrm{OP}=$ Organizational Performance

From data analysis, the study able to create a Structural Equation Model for Worker's Job Satisfaction and Organization Performance as follows:

$$
\begin{aligned}
& \mathrm{WJS}=0.39 * \mathrm{TL}, \text { Errorvar. }=0.59, R^{2}=0.41 \\
& \text { (0.051) }
\end{aligned}
$$

$$
\begin{array}{ccc}
\mathrm{OP}=0.48 * \mathrm{WJS}+0.035 * \mathrm{TL}, & \text { Errorvar. } & =0.43, R^{2}=0.57 \\
(0.054) & (0.050) & (0.043) \\
8.95 & 0.71 & 10.06 \\
\multicolumn{3}{c}{\text { (Source: } \text { LISREL OUTPUT 8.70) }}
\end{array}
$$

The result of all hypothetical tests indicates that all hypotheses tested on all respondents are supported by data.

Hypothesis 1: There is a positive effect between the transcendental leadership and the workers job satisfaction because $t$-value $>2(7.07>2)$, with the rate of effect 0.39 . The leader can enhance the leadership effect on employee job satisfaction [24] by helping in the maintenance of interpersonal/interdependent relationships, and keeps employee attention focused on goal achievement. Transcendental leadership is associated with job satisfaction through its attributes of vision, expectation, modeling, stimulation, support, and attainment of the group goal [25].

Hypothesis 2: There are strong effects of overall workers job satisfaction into the organization performance. Workers job satisfaction has the highest effect into organization performance, because $t$-value $>2(8.95>2)$, with the rate of effect 0.48. Heskett, et al. [26] suggest that satisfied employees will deliver high service quality. Higher employee satisfaction levels lead to high customer satisfaction, and ultimately affect customer loyalty and profitability.

Hypothesis 3: There is an effect between the transcendental leadership and the organization performance, with the t-value $<2(0.71<2)$, with the rate of effect 0.04 . Leadership behaviors such as problem solving and providing workers relevant information about decisions, plans, and activities are particularly important to increase organization performances [27].

Theoretical Implication. This study proved the first hypothesis which stated that transcendental has a significant effect into worker's job satisfaction. The leader must be able to empower their employees by encouraging them to finish the job on-time, create a good cooperation among divisions to avoid conflict and maintain a good relationship at all level organization by implementing an open communication system. The study also showed that transcendental leadership doesn't have significance effect into organization performance. This study also supported the previous study done by some researcher. Lowder [28] stated that leadership is the ability to inspire confidence and support among the people who are needed to achieve organizational goals Worker's job satisfaction has the highest effect into organization performance. The success of the workers in serving the customer needs is also highly dependent with the active involvement and participation of their supervisors. This data results supported the previous research said that employee job satisfaction exerts a significant positive effect on customer satisfaction.

Managerial Implication. The results of this study also have original implications for businesses that workers job satisfaction has the most significant effects into the organization performances and the role of transcendental leadership is needed to make workers satisfied. The companies must regularly give appropriate training and establish a corporate value that are put the customers as the top priority.

Suggested Further Research. First, it is very important for further studies to consider other variables that can affect the organization performance, such as: organization reputation; CRM; IT and any other factors that might have dominant effect to increase the organization performance. Second, the futures studies are being required to further to develop versions of the usage of SEM analyze methods with more diversified respondents from different organizations to get more generalized data analysis. Third, considering the concept of CSR as an important variable for the further studies.

\section{REFERENCES}

[1] J. Palmer, "Spirituality at work," Business Record, vol. 17, pp. 15-22, 2001.

[2] P. Harris, "Embracing spirituality in the workplace: A case study of employee's perception of increased job performance," Ph.D. thesis, Capella University, United States - Minnesota, 2010.

[3] F. Karakas, "Spirituality and performance in organizations: A literature review," Journal of Business Ethics, vol. 94, no. 1, p. 89, 2010.

[4] I. I. Mitroff and E. A. Denton, A spiritual audit of corporate America: a Hard Look at Spirituality, Religion, and Values in the Workplace, San Francisco: Jossey-Bass, 1999.

[5] P. Simanungkalit, "Booming of property industry in Indonesia," Marketers, August 2013.

[6] I. Soltani and R. B. Joneghani, "Operational model of cascading values and professional ethics in organization: a context for spiritual development of employees," International Journal of Business and Management, vol. 7, no. 18, pp. 130-140, 2012.

[7] Shabnam and N. S. Tung, "Intelligence, emotional and spiritual quotient as elements of effective leadership," Pertanika Journal of Social Sciences and Humanities, pp. 318-328, 2012.

[8] B. Panahi and A. Abedinpoor, Identification of Spiritual Organizations: Theories and Models, 2012.

[9] L. W. Fry, "Spiritual leadership as a model for student inner development," Journal of Leadership Studies, vol. 3, no. 3, 2009.

[10] D. Zohar and I. Marshall, SQ: Connecting with Our Spiritual Intelligence, London: Bloombury, 2000.

[11] D. Sisk and E. P. Torrance, Spiritual Intelligence: Developing higher consciousness, Buffalo, New York: Creative Education Foundation Press, 2001.

[12] R. Abidin, and A. H. MR, "The impact of spiritual intelligence on work performance: Case studies in government hospitals of east coast of Malaysia," The Macrotheme Review, vol. 2, no. 3, pp. 46-59, Spring 2013.

[13] G. L. Campuzano and S. S. Seteroff, "A new approach to a spiritual business organization and employee satisfaction," Eastern Academy of Management, 2009.

[14] A. Mohamed, J. Wisnieski, M. Askar, and A. Syed, "Towards a theory of spirituality in the workplace," Competitiveness Review, vol. 14, pp. 102-108, 2004. 
[15] I. I. Mitroff and E. A. Denton, A Spiritual Audit of Corporate America: a Hard Look at Spirituality, Religion, and Values in the Workplace, San Francisco: Jossey-Bass, 1999.

[16] A. Khorsidi and M. G. Ebaadi, "Relationship between spiritual intelligence and job satisfaction," Journal of Applied Environmental and Biological Science, vol. 2, no. 3, pp. 130-133, 2012.

[17] B. M. Bass and B. J. Avolio, Transformational Leadership: A Response to Critiques, The Free Press, New York, NY, 1993.

[18] B. Panahi and A. Abedinpoor, Identification of Spiritual Organizations: Theories and Models, 2012.

[19] L. M. Kendall and C. L. Hulin, The Job Descriptive Index, Rand McNelly, Chicago, 1969.

[20] F. J. Landy, L. J. Shankster, and S. S. Kohler, "Personnel selection and placement," Annual Review of Psychology, vol. 45, pp. 261-296, 1994.

[21] R. H. Chenhall and L. S. Kim, "Multiple perspectives of performance measures," European Management Journal, vol. 25, iss. 4, Pergamon, UK, pp. 266-282, 2007.

[22] J. F. Hair, W. C. Black, B. J. Babin, and R. E. Anderson, Multivariate data analysis, Pearson Education, New Jersey, 2010.

[23] J. Nunnaly, Psychometric Theory, New York: McGraw-Hill, 1978.

[24] J. A. Conger and R. N. Kanungo, "The empowerment process: Integrating theory andpractice," Academy of Management Review, pp. 471-482, 1988.

[25] B. M. Bass and B. J. Avolio, Transformational Leadership: A Response to Critiques, The Free Press, New York, NY, 1993.
[26] J. L. Heskett, W. E. Sasser, and L. A. Schlesinger, The Service Profit Chain: How Leading Companies Link Profit and Growth to Loyalty, Satisfaction, and Value, Free Press, New York, NY, 1994.

[27] B. M. Bass, Leadership and Performance beyond Expectations, The Free Press, New York, NY, 1985.

[28] T. Lowder, Aligning Spiritual Intelligence, Workplace Spirituality, and Organizational Culture: A New Domain for Superior Organizational Performance, Saint Leo University, 2011.

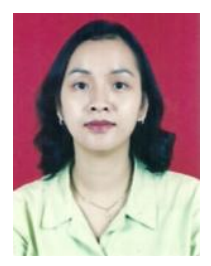

Florentina K. Tehubijuluw was born in Jakarta on April 14, 1974. She earned her bachelor degree in business administration within four years by Cum-Laude from University of Indonesia, Jakarta, Indonesia in 1996. Her master degree in business management was earned from Asian Institute of Management, Manila, Philippines in 1999. Her doctoral economics degree was earned within four years by Cum-Laude from Trisakti University, Jakarta, Indonesia in 2014.

Currently she has a managerial position as the vice president for Financial and Administration Program at STMIK Jibes and STIE Wiyatamandala, and in the same time, she is also as a lecturer in this institution teaching management and marketing courses. She is actively involved in the religious activities and holds some strategic position in religious institution especially related with the human capital development. She also plays actively as a public speaker and lecturer in some universities and private companies in Indonesia related with the economic and management studies. 